\title{
LASER-ARC WELDING OF HIGH-STRENGTH STEELS WITH YIELD STRENGTH OF MORE THAN 700 MPa
}

\author{
V.D. POZNYAKOV, V.D. SHELYAGIN, S.L. ZHDANOV, A.A. MAKSIMENKO, \\ A.V. ZAVDOVEEV and A.V. BERNATSKY \\ E.O. Paton Electric Welding Institute, NASU \\ 11 Bozhenko Str., 03680, Kiev, Ukraine. E-mail: office@paton.kiev.ua
}

\begin{abstract}
For the first time the prospects of using laser heat sources, namely for hybrid laser-arc welding, which allows improving the strength values of welded joints and their resistance to brittle and delayed fracture due to transformation of thermal cycle of welding, characteristic for arc processes, are shown for high-strength low-alloyed steels of small thicknesses on the example of steel 14KhGN2MDAFB. 8 Ref., 2 Tables, 3 Figures.
\end{abstract}

K e y words: hybrid laser-arc welding, high-strength steel, welding thermal cycles, structure, properties

Up to nowadays the use of arc discharge as one of the most widespread and cheap types of heat sources for welding encounters significant difficulties associated with insufficient concentration of energy in the electric-arc plasma and instability of arc burning at high welding speeds. Therefore, at the moment, the hybrid welding methods, such as laser-arc, laser-light beam, dual-beam, laser-induction and laser-plasma ones, are rapidly developed.

Among them the most perspective method for producing welded joints of high-strength steels is hybrid laser-arc welding (HLAW). This process is based on combination of technologies of laser welding and arc welding in shielding gases. The advantages of laser welding are determined by the possibility of joining metals of small thicknesses with a minimum introducing of heat into the product, the high accuracy and welding speed. At the same time, such disadvantages as need in providing minimum gap between the surfaces being welded and need in using high-power lasers are not inherent in hybrid laser welding [1]. Although the limited heat input in laser and HLAW leads to formation of hardening structures in the weld metal and HAZ of high-strength steel, the advantages of these methods before arc welding consist in the minimum deformation of welded joint under the effect of welding thermal cycle [2].

Due to its significant advantages the hybrid welding is a quite reliable method for joining materials, and the area of its application in recent years includes many fields of industry, such as shipbuilding, automotive, manufacture of containers, truck cranes and road building machinery [3].
Like in other welding processes the capabilities of hybrid laser-MAG welding are determined by appropriate selection of main parameters of the process, which can be obtained by varying the necessary operational characteristics, such as penetration depth, weld shape and metallurgical properties of welded joint. An important factor for hybrid welding is the choice of shielding gas. For Nd:YAG laser this choice is determined by the requirements of arc burning stability, quality of weld protection, as well as need in filler metal transfer without spattering. In work [4] it is noted that to meet such requirements it is optimal to use the shielding $\mathrm{Ar}+18 \% \mathrm{CO}_{2}$ gas mixture.

At the present time a sufficient number of publications has been already available regarding the use of laser and HLAW of low-carbon and low-alloy steels St3, 09G2S, X70 etc. [5-7]. This paper considers the use of laser heating sources for welding of hardening steels with bainiticmartensitic structure, the yield strength of which exceeds $700 \mathrm{MPa}$.

The main difficulties in welding of HSLA steels are associated with the need in preventing the cold crack formation in the HAZ metal of welded joint, as well as preventing the structures, which sharply reduce the resistance of welds to brittle fracture. Moreover, the required operational and technological properties of welded joints must be acquired in the postweld state without additional heat treatment [8]. In this regard, the aim of this work consists in the comparative evaluation of thermal cycles, structure and mechanical properties of joints of highstrength steel characteristic for laser, HLAW and arc welding.

Experimental procedure. As the object of investigations, 14KhGN2MDAFB high-strength 

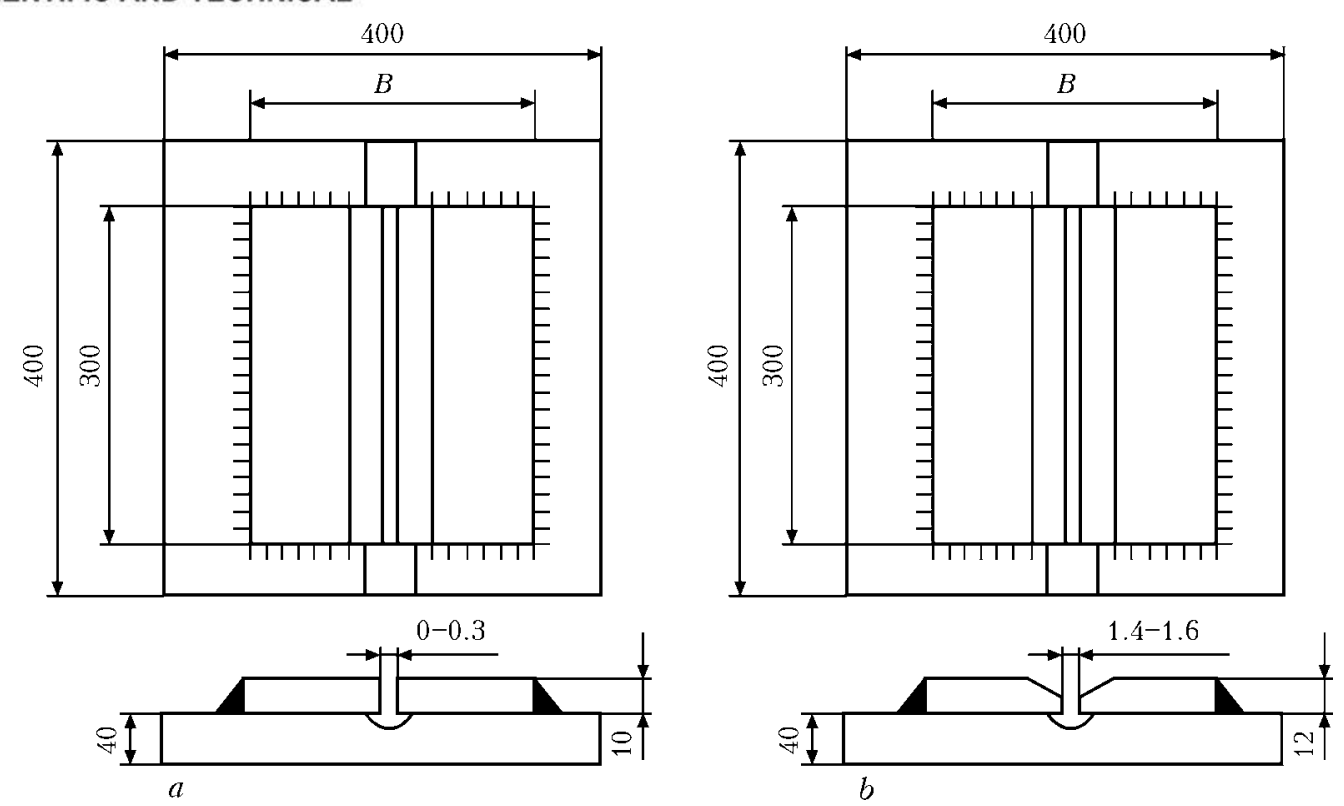

Figure 1. Technological sample with adjustable rigidity for hybrid and laser $(a)$ and arc $(b)$ welding

steel of $8 \mathrm{~mm}$ thickness was chosen of the following chemical composition, wt.\%: $0.14 \mathrm{C}$; $0.3 \mathrm{Si} ; 0.98 \mathrm{Mn} ; 1.19 \mathrm{Cr} ; 2.07 \mathrm{Ni} ; 0.22 \mathrm{Mo} ; 0.08 \mathrm{~V}$; $0.45 \mathrm{Cu} ; 0.06 \mathrm{Nb} ; 0.005 \mathrm{~S} ; 0.018 \mathrm{P}$. To determine the parameters of thermal cycles during heatingcooling the chromel-aluminum thermocouples of $0.5 \mathrm{~mm}$ diameter were used, the thermojunction of which was deepened into marks, where the overheat area of HAZ was supposed to be.

Applying the integrated method of investigations, which includes optic and electron microscopy, the structural and phase changes in welded joints were studied, and the mechanical tests of specimens for tension and impact bending were applied to study their properties.

The important factor is producing welded joints without cold cracks. In order to determine

Table 1. Conditions of $14 \mathrm{KhGN2MDAFB}$ steel welding

\begin{tabular}{||l|c|c|c|c|c||}
\hline \multirow{2}{*}{ Method } & \multicolumn{5}{|c||}{ Welding modes } \\
\cline { 2 - 6 } & $\begin{array}{c}v_{\mathrm{w}}, \\
\mathrm{m} / \mathrm{h}\end{array}$ & $I_{\mathrm{w}}, \mathrm{A}$ & $U_{\mathrm{a}}, \mathrm{V}$ & $\begin{array}{c}v_{\text {sh.g, }} \mathrm{l} / \mathrm{min} \\
\text { Arc }\end{array}$ & $\begin{array}{c}\text { Heat } \\
\text { input, } \\
\mathrm{J} / \mathrm{cm}\end{array}$ \\
\hline Arc & 30 & 230 & 31 & 14 & 10700 \\
\hline Arc & 40 & 230 & 31 & 14 & 4825 \\
\hline Arc & 50 & 230 & 31 & 14 & 3852 \\
\hline Laser & 40 & - & - & 14 & 3170 \\
\hline Laser & 50 & - & - & 14 & 2540 \\
\hline Hybrid & 72 & 125 & 23 & 30 & 2900 \\
\hline Hybrid & 90 & 150 & 25 & 30 & 2570 \\
\hline Hybrid & 110 & 200 & 26 & 30 & 2430 \\
\hline Note. Laser power - $4.4 \mathrm{~kW}$. \\
\hline
\end{tabular}

the opportunities for producing quality welded joints without formation of these inadmissible defects, the investigations were carried out using rigid butt technological sample with an adjustable fixing rigidity. The sample represented a massive slab of $400 \times 400 \times 40 \mathrm{~mm}$ in size, on which the butt joints of steel $14 \mathrm{KhGN} 2 \mathrm{MDAFB}$ of $300 \mathrm{~mm}$ length and $10 \mathrm{~mm}$ thickness without edge preparation (Figure 1, $a$ ) and with a gap of $0.1-0.3 \mathrm{~mm}$ were installed and welded by fillet weld around the perimeter for hybrid and laser welding, and for comparison with the arc welding method, the joint of $12 \mathrm{~mm}$ thickness with $\mathrm{V}$ shaped edges bevel and $5 \mathrm{~mm}$ root face (Figure 1, b) was produced to provide the technological lack of penetration, being a stress concentrator for initiating the cracks formation. The preset level of hardness was determined by width of butt joint (100 and $200 \mathrm{~mm}$ ).

To compare the conditions of heating-cooling, welded butt joints of steel 14KhGN2MDAFB were produced using automatic arc method in shielding gases, laser and HLAW. The welding conditions are shown in Table 1.

Automatic arc welding using solid wire Sv10KhN2GSMFTYu of $1.2 \mathrm{~mm}$ diameter in $\mathrm{Ar}+$ $+18 \% \mathrm{CO}_{2}$ mixture was carried out on the conditions providing the constancy of current, voltage and shielding gas mixture: $I_{\mathrm{w}}=220-240$ A, $U_{\mathrm{a}}=30-32 \mathrm{~V}, v_{\text {sh.g }}=14-16 \mathrm{l} / \mathrm{min}$. At the same time the welding speed was changed in the ranges of $18,30,40$ and $50 \mathrm{~m} / \mathrm{h}$.

In laser process the welding speed was in the ranges from 40 to $50 \mathrm{~m} / \mathrm{h}$. At $\mathrm{Nd}$ :YAG laser power of $4.4 \mathrm{~kW}$, deepening of focus was $\Delta F=$ $=-1.5 \mathrm{~mm}$. 
To provide the quality welded joint of $8 \mathrm{~mm}$ thickness with a required penetration depth the conditions of laser component in HLAW were similar to those in the laser process, and in arc component the electrical parameters were changed together with the welding speed at constant consumption of shielding gas $v_{\text {sh.g }}=$ $=30 \mathrm{l} / \mathrm{min}\left(\mathrm{Ar}+18 \% \mathrm{CO}_{2}\right)$. In HLAW for $v_{\mathrm{w}}=72 \mathrm{~m} / \mathrm{h} I_{\mathrm{w}}=125 \mathrm{~A}$ and $U_{\mathrm{a}}=23 \mathrm{~V}$; for $v_{\mathrm{w}}=90 \mathrm{~m} / \mathrm{h}-I_{\mathrm{w}}=150 \mathrm{~A}$ and $U_{\mathrm{a}}=25 \mathrm{~V}$; for $v_{\mathrm{w}}=110 \mathrm{~m} / \mathrm{h}-I_{\mathrm{w}}=200 \mathrm{~A}$ and $U_{\mathrm{a}}=26 \mathrm{~V}$.

Obtained results and their discussion. The analysis of thermal cycles, obtained in laser and HLAW methods, showed that as compared to the conventional process of automatic arc welding in shielding gases the heating rate of $\mathrm{HAZ}$ metal up to $1100-1300{ }^{\circ} \mathrm{C}$ and the cooling rate of overheat areas in the temperature range of $600-500{ }^{\circ} \mathrm{C}\left(w_{6 / 5}\right)$ are $4-5$ times increased ( $\mathrm{Fi}-$ gure 2).

Laser and HLAW are characterized by the tendency of increasing the cooling rate, but if in the first case (Figure $2, d$ ) the difference in $w_{6 / 5}$ is observed during the change of welding speed $\left(w_{6 / 5}=65{ }^{\circ} \mathrm{C} / \mathrm{s}\right.$ at $v_{\mathrm{w}}=40 \mathrm{~m} / \mathrm{h}$ and $103{ }^{\circ} \mathrm{C} / \mathrm{s}$ $T,{ }^{\circ} \mathrm{C}$
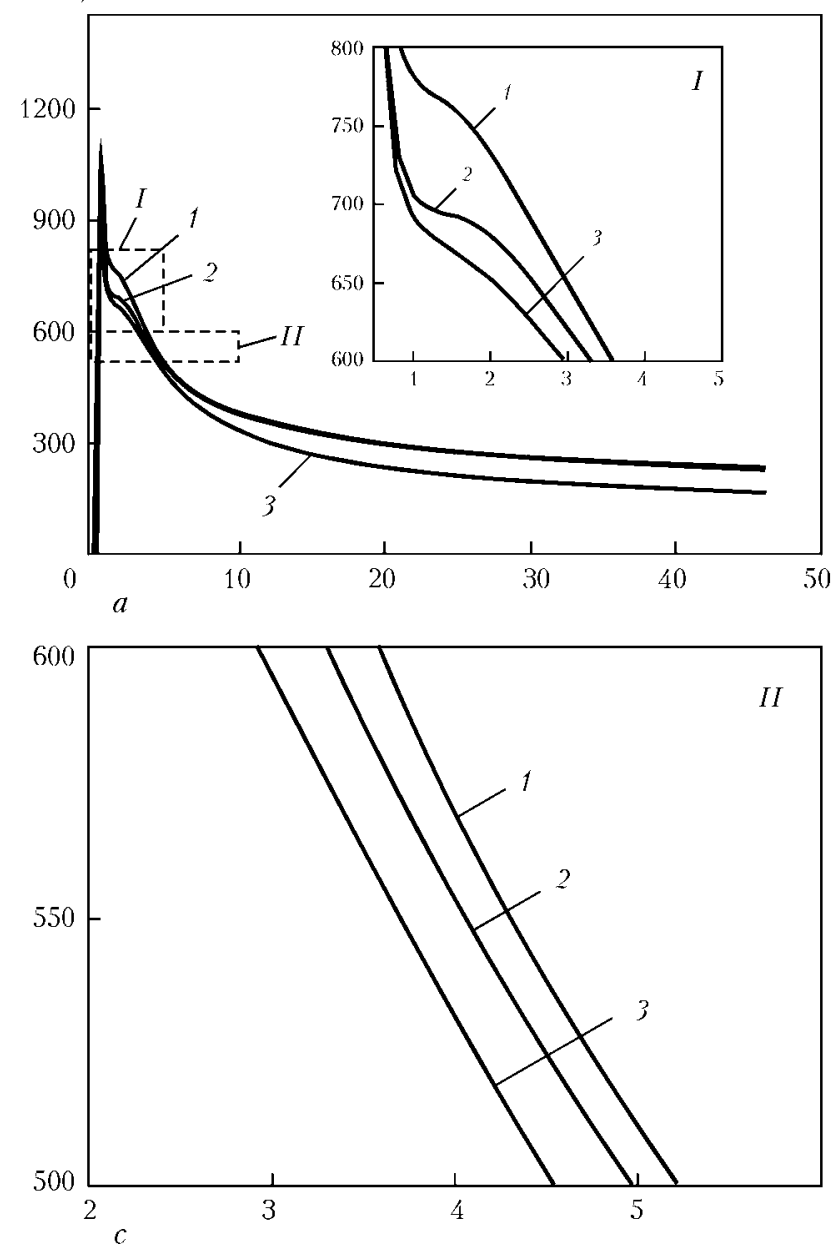

at $50 \mathrm{~m} / \mathrm{h})$, then at different speeds of HLAW: $v_{\mathrm{w}}=72,90$ and $110 \mathrm{~m} / \mathrm{h}$ (Figure $2, c$ ) $w_{6 / 5}$ are approximately the same and amount to 58$63{ }^{\circ} \mathrm{C} / \mathrm{s}$. Moreover, in laser welding at the range from 600 to $500{ }^{\circ} \mathrm{C}$, the cooling of metal occurs in 2 and $4 \mathrm{~s}$ for the welding speeds of 50 and $40 \mathrm{~m} / \mathrm{h}$, respectively, whereas for HLAW the time of passing the given temperature range is the same and amounts to $1.5 \mathrm{~s}$.

Also the temperature range from 800 to $600{ }^{\circ} \mathrm{C}$ should be noted. Whereas in laser welding a monotonous decrease of cooling curves (Figure 2, $b$, insert to the right) is observed, then in HLAW the S-shaped behavior of cooling curves is observed, moreover for $v_{\mathrm{w}}=90 \mathrm{~m} / \mathrm{h}$ the horizontal area is the most expressed (Figure 2, $a$, insert to the right). Apparently, it can be explained by different heat input into the welded joint and, hence, by different effect of power characteristics and the separately taken laser heating source, as well as the total effect of laser and arc, which even at increase in welding speed transforms thermal cycle towards decrease of the cooling rate.

It should be noted that in HLAW the cooling rate is approximately 2 times higher than that in
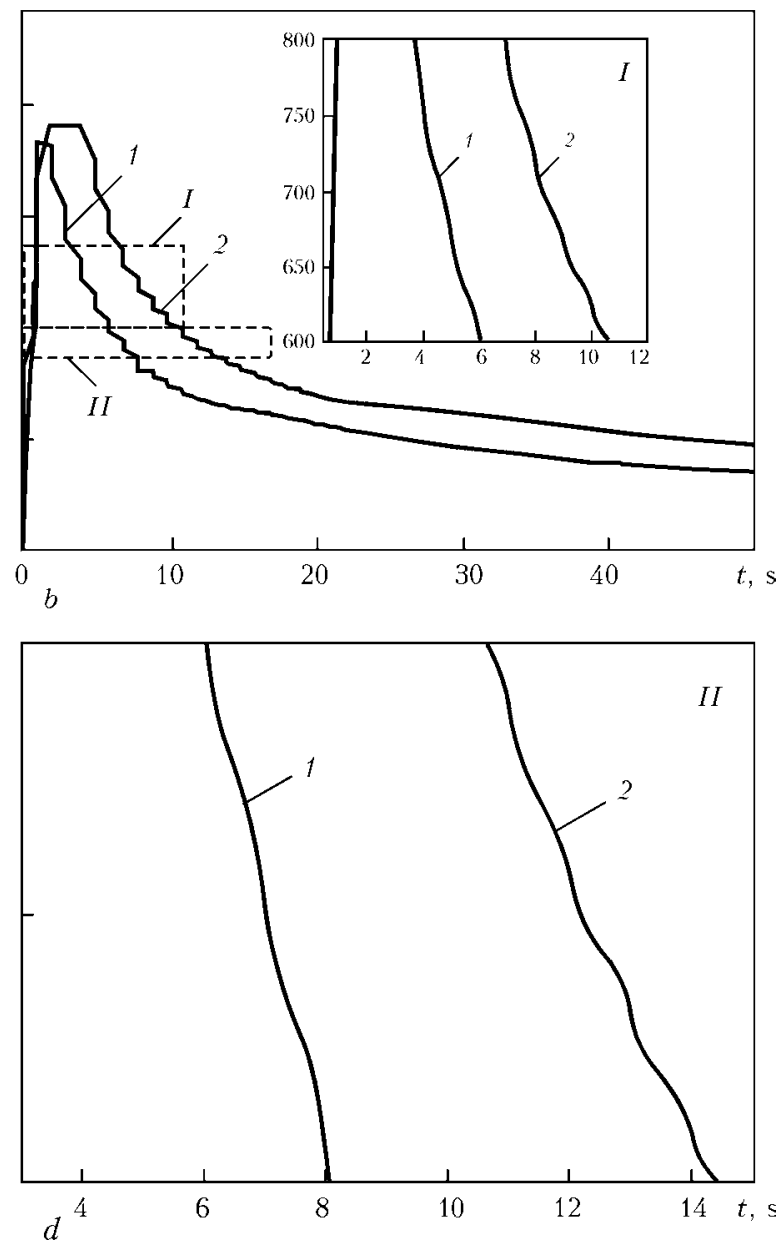

Figure 2. Thermal cycles in $\operatorname{HLAW}(a, c)$ at $v_{\mathrm{w}}=72(1), 90(2)$ and $110(3) \mathrm{m} / \mathrm{h}$, and in laser welding $(b, d)$ at $v_{\mathrm{w}}=$ $=50(1)$ and $40(2) \mathrm{m} / \mathrm{h}$ 
SCIENTIFIC AND TECHNICAL

Table 2. Mechanical properties of base and weld metal of steel 14HGN2MDAFB joints in different welding methods

\begin{tabular}{|c|c|c|c|c|c|c|c|c|}
\hline \multirow{3}{*}{\begin{tabular}{|l} 
Method \\
BM \\
\end{tabular}} & \multirow{3}{*}{$v_{\mathrm{w}}, \mathrm{m} / \mathrm{h}$} & $\sigma_{0.2}$ & $\sigma_{\mathrm{t}}$ & \multirow{3}{*}{$\begin{array}{c}\delta_{5} \\
\% \\
20 \\
\end{array}$} & \multicolumn{3}{|c|}{$K C V, \mathrm{~J} / \mathrm{cm}^{2}$, at $T,{ }^{\circ} \mathrm{C}$} & \multirow{3}{*}{$\begin{array}{c}\begin{array}{c}\text { Type of } \\
\text { structure } \\
\text { (weld } / \text { HAZ) }\end{array} \\
\text { B }\end{array}$} \\
\hline & & \multicolumn{2}{|c|}{$\mathrm{MPa}$} & & +20 & -20 & $\begin{array}{c}-40 \\
\text { (weld } / \mathrm{HAZ} \text { ) }\end{array}$ & \\
\hline & & 780 & 820 & & - & - & 35 & \\
\hline Arc & 30 & 625 & 739 & 20 & 75 & 50 & $37 / 42$ & $\mathrm{~B} / \mathrm{B}-\mathrm{M}$ \\
\hline Arc & 40 & 680 & 778 & 20 & 97 & 94 & $80 / 52$ & $\mathrm{~B} / \mathrm{B}-\mathrm{M}$ \\
\hline Arc & 50 & 798 & 911 & 16 & 103 & 95 & $53 / 148$ & $\mathrm{~B}-\mathrm{M} / \mathrm{B}-\mathrm{M}$ \\
\hline Laser & 40 & 858 & 925 & 11 & 53 & 23.8 & 14 & $\mathrm{~B}-\mathrm{M} / \mathrm{B}-\mathrm{M}$ \\
\hline Laser & 50 & 862 & 924 & 14 & 53 & 30.4 & 22.8 & $\mathrm{~B}-\mathrm{M} / \mathrm{B}-\mathrm{M}$ \\
\hline Hybrid & 72 & 907 & 1129 & 11 & 75.7 & 38.6 & $38.3 / 84$ & $\mathrm{~B} / \mathrm{B}$ \\
\hline Hybrid & 90 & 1147 & 1323 & 10 & 61.5 & 54 & $52.1 / 59$ & $\mathrm{~B}-\mathrm{M} / \mathrm{B}$ \\
\hline Hybrid & 110 & 987 & 1083 & 12 & 70 & 50.3 & $35.8 / 84$ & $\mathrm{~B} / \mathrm{B}$ \\
\hline
\end{tabular}

automatic arc welding performed at maximum speed of $50 \mathrm{~m} / \mathrm{h}$, at which the quality weld can be still produced. The experiments showed that the further increase in welding speed in arc welding processes in shielding gases using welding wire of $1.0-1.2 \mathrm{~mm}$ diameter is not rational.

Such differences of cooling conditions of the weld and HAZ metal of 14KhGN2MDAFB welded joints for the above-mentioned welding methods cause certain changes in their structure, and thus their mechanical properties are changed. The data presented in Table 2 show that with increase in arc welding speed the values of static strength of weld metal increase and its elongation decreases. This is explained by increase in cooling rate in $600-500{ }^{\circ} \mathrm{C}$ range and, consequently, by a more intensive hardening of metal.

In laser welding the values of elongation and impact toughness are reduced, as compared to those of the base metal at testing temperature of $-40{ }^{\circ} \mathrm{C}$ (by 30 and $50 \%$, respectively). The strength characteristics remain almost unchanged as compared to the initial state.

Unlike in laser method, in HLAW the growth of strength and impact toughness of weld metal by $30-40 \%$ as compared to the initial state of metal and the similar decrease (the same as in laser welding) of values of elongation are observed. Such regularities are characteristic for $v_{\mathrm{w}}=90 \mathrm{~m} / \mathrm{h}$. The increase in speed of hybrid welding of up to $110 \mathrm{~m} / \mathrm{h}$ results in decrease in strength and impact toughness to the level of values typical for $v_{\mathrm{w}}=72 \mathrm{~m} / \mathrm{h}$.

It was found in the process of carried out investigations of structural and phase changes in the weld and HAZ of $14 \mathrm{KhGN} 2 \mathrm{MDAFB}$ welded joints that with increase in speed of laser welding from 18 to $50 \mathrm{~m} / \mathrm{h}$ and in speed of HLAW from 72 to $90 \mathrm{~m} / \mathrm{h}$ the phase composition of weld metal is changed from bainitic (B) to bainiticmartensitic (B-M). For the base 14KhGN2MDAFB metal the bainitic-ferritic (BF) structure with grain size $D_{\mathrm{g}} \sim 5-24 \mu \mathrm{m}$ and microhardness $H V$ 2740-2850 $\mathrm{MPa}$ are characteristic. Using $\mathrm{CO}_{2}$-laser at low speeds of laser welding up to $18 \mathrm{~m} / \mathrm{h}$ the bainitic structure with $D_{\mathrm{g}} \sim 40-80 \times 150-400 \mu \mathrm{m}$ and microhardness $H V 2850-3510 \mathrm{MPa}$ is formed in the weld. The further increase in welding speed up to $50 \mathrm{~m} / \mathrm{h}$, as was shown by the present investigations using $\mathrm{Nd}$ :YAG laser, leads to the formation of M-B structure with the more uniform grains at coefficient of their shape $\chi=2-3$ and microhardness of up to $H V 4170 \mathrm{MPa}$ both in the weld, as well as in the HAZ metal. At the same time, according to the TEM data, the size of bainitic packets decreases in the overheat areas of HAZ by 1.5 times, and the width of laths in bainitic structures by 1.3-2 times. Such structural changes, apparently, lead to reduction in the values of ductility and impact toughness of weld metal in laser welding.

The use of HLAW process, as was already mentioned, results in increase of welding speeds and electrical parameters of arc component, which, in its turn, provides approximately the same heat input into the welded joint. The values of heat input of welding amounted to 2.4$2.9 \mathrm{~kJ} / \mathrm{cm}$, moreover, the parameters of the structure at different welding speeds were changed, which resulted in difference between the values of mechanical properties of the weld metal.

Thus, in HLAW at $v_{\mathrm{w}}=72 \mathrm{~m} / \mathrm{h}$ the phase composition of the weld and HAZ is bainitic (mostly the lower one), the gradients according to microhardness between the structural components are minimal at refinement of grain by approximately 3-4 times (Figure $3, a, b$ ). The in- 


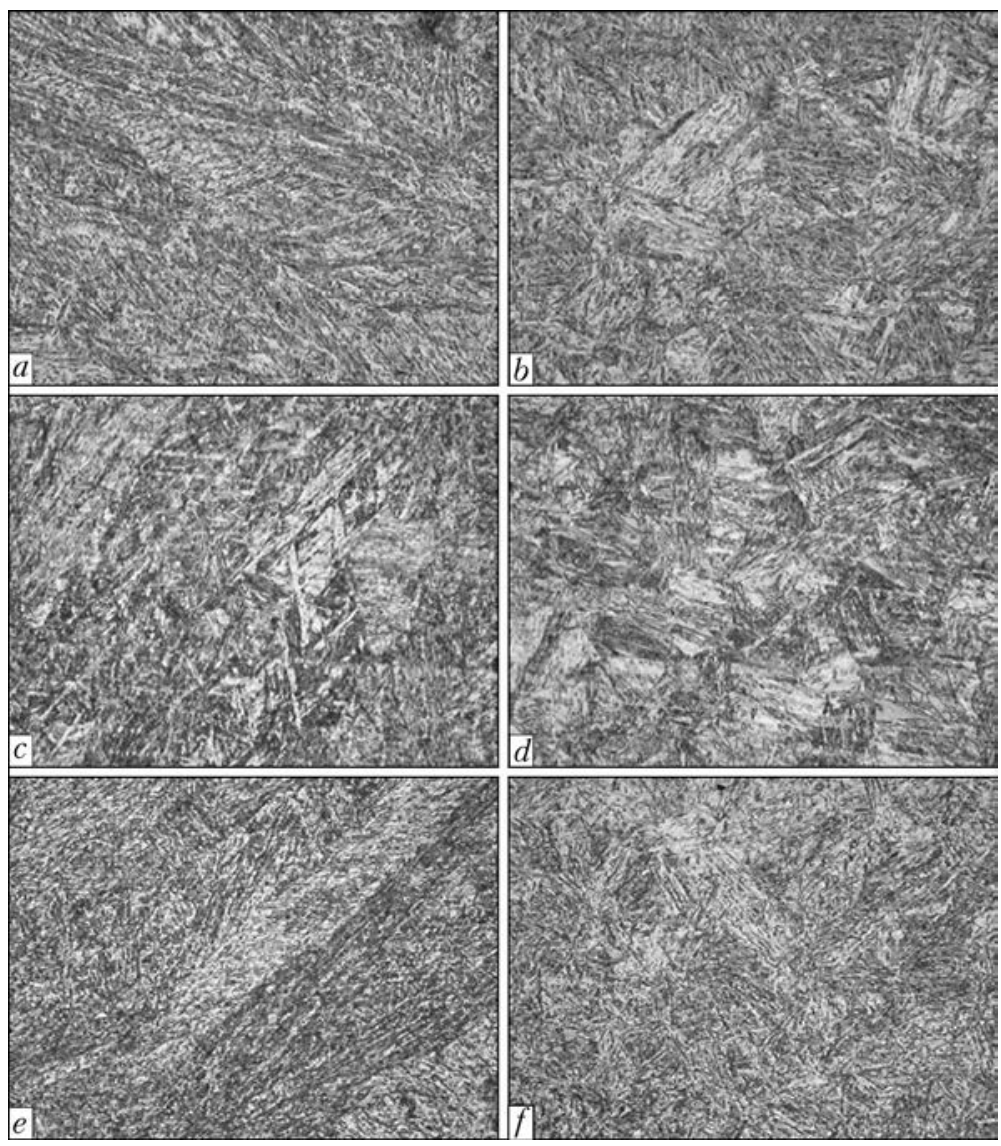

Figure 3. Microstructure $(\times 500)$ of weld and HAZ metal at different HLAW conditions: $a, c, e-$ weld; $b, d, f-$ HAZ; $a, b-v_{\mathrm{w}}=72 ; c, d-90 ; e, f-110 \mathrm{~m} / \mathrm{h}$

crease in welding speed up to $90 \mathrm{~m} / \mathrm{h}$ results in changing the phase composition at transition from the weld to HAZ from $\mathrm{B}-\mathrm{M}(\mathrm{M}>\mathrm{Bl}>\mathrm{Bu})$ in the weld to bainitic $(\mathrm{Bl}>\mathrm{Bu})$ in the HAZ (Figure 3, $c, d$ ). It causes increase in mechanical properties $\sigma_{0.2}, \sigma_{t}, K C V$ (see Table 2). In this case the martensitic component provides increment of strength characteristics, and the presence of lower bainite provides improvement of impact toughness. Apparently, such features of structure formation are caused by difference in behavior of the metal during cooling at $800-600{ }^{\circ} \mathrm{C}$. In hybrid welding at $v_{\mathrm{w}}=110 \mathrm{~m} / \mathrm{h}$ the phase composition at transition from the weld to $\mathrm{HAZ}$ is bainitic (Figure 3,e,f), moreover $\mathrm{Bl}<\mathrm{Bu}$, and gradients according to microhardness between the structural components both in the weld $(\triangle H V$ up to $310 \mathrm{MPa})$, as well as in the HAZ $(\Delta H V$ up to $510 \mathrm{MPa})$ are significant, which leads to reduction of strength and impact toughness of the weld metal (see Table 2).

As a result of carried out investigations on resistance to cold crack formation it was established that in arc welding of rigid butt joints of steel $14 \mathrm{KhGN} 2 \mathrm{MDAFB}$ with width of 100 and $200 \mathrm{~mm}$ at $v_{\mathrm{w}}=18 \mathrm{~m} / \mathrm{h}$, they damage the weld along the whole length and the whole cross-section. Under the given conditions of cooling of
HAZ metal at $w_{6 / 5}=20{ }^{\circ} \mathrm{C} / \mathrm{s}$ the unfavorable factors from the point of view of cold crack formation are the concentration of diffusion hydrogen in the deposited metal of up to 1.5$2.0 \mathrm{ml} / 100 \mathrm{~g}$, and the features of fine structure formation, being nonuniform according to grain size, the values of microhardness and dislocation density, varied from (2-3) $10^{10}$ to $10^{11} \mathrm{~cm}^{-2}$ and characterized by a nonuniform distribution. Such differences in the distribution of dislocations and their density result in the formation of essential microstresses in the metal that probably, has a negative affect on resistance of welded joints to cold crack formation.

As was shown by the experiments, the increase in resistance to cold crack formation in welded joints of steel $14 \mathrm{KhGN2MDAFB}$ is possible by increase in arc welding speed up to $50 \mathrm{~m} / \mathrm{h}$, at the same time reducing the heat input by $1.7-2.6$ times. The similar effect is achieved in laser welding at the same speed and in HLAW at $v_{\mathrm{w}}=72$, 90 and $110 \mathrm{~m} / \mathrm{h}$. Moreover, the content of diffusion hydrogen in the deposited metal decreases to $0.2-0.4 \mathrm{ml} / 100 \mathrm{~g}$, and in laser welding it decreases in the molten metal to $0.07 \mathrm{ml} / 100 \mathrm{~g}$. From the point of view of structure the dislocations are uniformly distributed in the volume of metal, and their density is within $(5-6) \cdot 10^{10} \mathrm{~cm}^{-2}$, more- 
over, due to the lower density of dislocations and their uniform distribution the microstresses are decreased in values.

Thus, the optimum way to provide the high mechanical properties and values of impact toughness of weld metal of joints of steel $14 \mathrm{KhGN} 2 \mathrm{MDAFB}$ is HLAW performed at $v_{\mathrm{w}}=$ $=90 \mathrm{~m} / \mathrm{h}$. The use of HLAW at the abovementioned conditions at $v_{\mathrm{w}}=72$ and $110 \mathrm{~m} / \mathrm{h}$ satisfies the conditions providing values of impact toughness at the level of $K C V_{-40}>30 \mathrm{~J} / \mathrm{cm}^{2}$.

\section{Conclusions}

As a result of carried out investigations the advantages and disadvantages of HLAW are shown as compared to laser and arc welding. Thus, it was established that the benefit of HLAW is the most economical efficiency at high technological values. In particular, despite the higher values of metallurgical and mechanical properties of welded joints of steel 14KhGN2MDAFB, HLAW provides a significant increase in welding speeds, at the same time maintaining a high level of properties of welded joints. Moreover, the use of the laser source in hybrid process allows significant reduction of diffusion hydrogen content and den- sity of dislocations in weld metal. The combinations of such characteristics are impossible to be achieved using only laser or arc welding.

1. Grigoriants, A.G., Shiganov, I.N., Chirkov, A.M. (2004) Hybrid technologies of laser welding: Manual. Moscow: N.E. Baumana MGTU.

2. Shelyagin, V.D., Khaskin, V.Yu., Garashchuk, V.P. et al. (2002) Hybrid $\mathrm{CO}_{2}$-laser and $\mathrm{CO}_{2}$ consumablearc welding. The Paton Welding J., 10, 35-37.

3. Kah, P., Salminen, A., Martikainen, J. (2010) Laserarc hybrid welding processes (Review). Ibid., 6, 32-40.

4. Shelyagin, V.D., Khaskin, V.Yu., Siora, A.V. et al. (2007) Gas-shielded laser and laser-arc welding of steels. Ibid., 1, 27-30.

5. Atabaki, M., Ma, J., Yang, G. et al. (2014) Hybrid laser /arc welding of advanced high-strength steel in different butt joint configurations. Materials and $D e-$ sign, 54, 573-587.

6. Unta, A., Lappalainena, E., Salminen, A. (2013) Autogenous laser and hybrid laser arc welding of Tjoint low alloy steel with fiber laser systems. Phys. Proc., 41, 140-143.

7. Sathiya, P., Mishra, M.K., Shanmugrarajan, B. (2012) Effect of shielding gases on microstructure and mechanical properties of super austenitic stainless steel by hybrid welding. Materials Design, 33, 203-215.

8. Musiyachenko, V.F., Mikhoduj, L.I. (1987) Arc welding of high-strength alloyed steels. Moscow: Mashinostroenie.

Received 01.07.2015 